\title{
Protection and Utilization of Medicinal Biological Resources to Address Cross-Border Risk Challenges
}

\author{
Yun Song ${ }^{1,2}$, Ming $\mathrm{Fu} \mathrm{Li}^{1,2 *}$ and Jin $\mathrm{Xu}^{1,2}$ \\ ${ }^{1}$ CAIQ center for Biosafety, Sanya 572025, China \\ ${ }^{2}$ Institute of Plant Quarantine, Chinese Academy of Inspection and Quarantine, Beijing 100176, China \\ *Corresponding author: Ming Fu Li, Institute of Plant Quarantine, Chinese Academy of Inspection and Quarantine, Beijing \\ 100176, China, Email: limf9@sina.com
}

\section{ARTICLE INFO}

Received: 㓞 December 01, 2021

Published: 幽 December 06, 2021

Citation: Yun Song, Ming Fu Li, Jin Xu. Protection and Utilization of Medicinal Biological Resources to Address Cross-Border Risk Challenges. Biomed J Sci \& Tech Res 40(3)-2021. BJSTR. MS.ID.006445.

\section{ABSTRACT}

Biological resources are the basis for human survival and development and have a direct bearing on our wellbeing. Humans must respect nature and follow its ways. Medicinal biological resources are important strategic biological resources, especially at the risk of loss and abuse. The cross-border trade based on economic interests has led to the over exploitation and abuse of biological species resources. A new pattern of biological resources conservation has largely taken shape, with improvements to the legal system, supervision mechanisms and governing capacity for eco-conservation, marking the beginning of a new era for biological resources conservation and utilization.

Keywords: Medicinal Biological Resources; Cross-Border Trade

\section{Introduction}

Biological resources are strategic resources for human survival and sustainable social development and have a direct bearing on our wellbeing, also the most basic component of biodiversity. Taking agriculture as an example, in the past few decades, new plant varieties have emerged one after another all over the world, and the grain yield per mu has reached new highs, which is due to the contribution of agricultural Germplasm. Biological species resources are at risk of loss and abuse. Climate change, environmental pollution, invasive species and deforestation, A special analysis carried out by the journal Nature indicates that an astonishing $41 \%$ of all amphibians on the planet now face extinction while $26 \%$ of mammals are similarly threatened [1]. The trade based on economic interests has led to the over exploitation and abuse of biological species resources, the development of new bioengineering technology has accelerated the possibility of biological resources becoming real productivity.

Medicinal biological resources are important strategic biological resources in the coming era. With the increasing demand for medicinal plants, the protection of related wild plants is also facing increasingly severe challenges. Among the 28187 medicinal plants recorded by (State of the World's Plants 2017) of the Kew Royal Botanical Gardens, 1280 are protected by the Convention on international trade in endangered species of wild animals and plants [2]. At present, the total annual demand of China's market exceeds 600000 tons, of which nearly 300000 tons are exported [3]. From 2008 to 2010, a total of 41 medical plant species and 285 batches, involving 55 countries and regions, were recorded at all the ports of Entry-Exit Inspection and Quarantine Bureau in China (except Tibet). A total of 276 batches ( $97 \%$ in total) were exported to 53 countries and regions. $70 \%$ of the varieties of commonly used Chinese herbal medicines still depend on wild resources. In the past 25 years, the output value of traditional Chinese medicine industry has increased by more than $20 \%$ annually. Some famous international pharmaceutical companies have strengthened the research and development of natural drugs.

The types and quantity of Chinese medicinal materials exported have increased significantly, and the large export of medicinal plant 
extracts has caused great pressure on wild medicinal biological resources. The protection of medicinal biological resources has become a key issue of biodiversity protection. Currently, as species worldwide are becoming extinct at an alarming rate, biodiversity loss and ecosystem degradation pose a major risk to human survival and development. The Convention on Biological Diversity came into effect, which set three objectives the conservation of biological diversity, the sustainable use of its components, and the fair and equitable sharing of the benefits arising out of the utilization of genetic resources, ushering in a new era for the protection of global biodiversity. There is systematic planning for biosecurity risk control and governance. Efforts have been made to improve the mechanism for preventing the invasion of alien species, promote the sound development of biotechnologies, and strengthen the protection, supervision and regulation of biogenetic resources. The aim is to protect nature and live in harmony with it.

ISSN: 2574-1241

DOI: 10.26717/BJSTR.2021.40.006445

Ming Fu Li. Biomed J Sci \& Tech Res

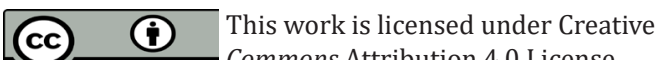

Submission Link: https://biomedres.us/submit-manuscript.php

\section{Conflicts of Interest}

The authors declare no competing interests.

\section{Funding Statement}

This work was supported by grants from Hainan Major Science and Technology Project (No. ZDKJ202002); the National Key Research and Development Program of China (2017YFF0210302, 2017YFF0210300).

\section{References}

1. R Monastersky (2014) Species are disappearing quickly-but researchers are struggling to assess how bad the problem is. Nature 516(7530): 158-159, a2.

2. (2017) State of the World's Plants. Royal Botanical Gardens, Kew.

3. (2008) Promulgation of Outline of National Planning for Conservation and Utilization of Biological Species Resources. The Chinese Livestock and Poultry Breeding 06: 7.

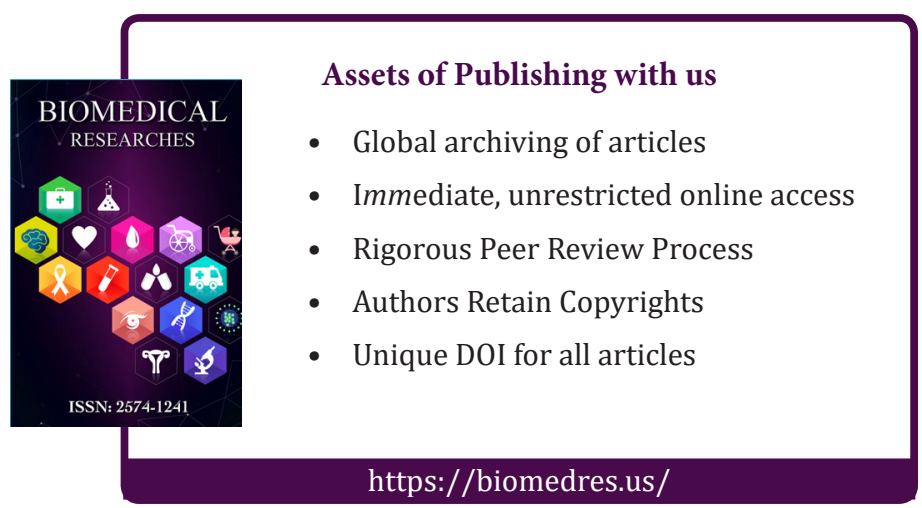

